\title{
Todos os dias sob chuva, sol ou frio: 0 infante pedinte sob a ótica da imprensa escrita (Criciúma, 1980)
}

\author{
Elisangela da Silva Machieski*
}

\author{
Palavras-chave: \\ História \\ Imprensa \\ Infância
}

Keywords:

History

Press

Childhood

\begin{abstract}
Resumo: Esse artigo tem por finalidade analisar, por meio da imprensa escrita, questões a cerca dos infantes e do ato de mendicância na cidade de Criciúma, na década de 1980. Durante esse período, notícias relacionadas ao público infantojuvenil ganhavam espaço na mídia impressa da cidade. As reportagens selecionadas foram coletadas do Jornal Tribuna Criciumense. Foram encontradas seis reportagens que tiveram como tema a mendicância de crianças e adolescentes e a pauta, quando referente a essa temática, seguiu por dois caminhos principais, denunciar o problema da mendicância e apontar caminhos para a sua solução.
\end{abstract}

\begin{abstract}
This article aims to analyze, through the written press, questions about the street kids and the act of begging in the city of Criciúma, in the 1980s. During this period, issues related to children and adolescents gained space in the printed media of the city. The selected reports were collected from Jornal Tribuna Criciumense. There were six reports that had as theme the begging of children and adolescents and the agenda, when referring to this theme, followed two main paths, denounce the problem of begging and point out ways to solve it.
\end{abstract}

Recebido em 31 de maio de 2017. Aprovado em 02 de agosto de 2017.

\section{Introdução}

O relógio da igreja matriz marcava $17 \mathrm{~h} 30$ quando Carlinhos, Rodrigo, Mateus, Pedro e Luiz ${ }^{1}$ sentaram em um dos bancos da Praça Nereu Ramos. Os meninos juntaram-se depois de um dia de muito corre-corre. Cada um tinha um roteiro diferente, mas a mesma tarefa: esmolar. Para um aqui, puxa outro ali e assim iam pedindo uns trocados. Estavam animados ao contabilizar a soma de mais de $60 \mathrm{mil}$ cruzeiros, valor que seria dividido entre os cinco. O grupo comemorava o sucesso daquele dia de "pedincha". Tamanha a euforia, não perceberam que eram observados. Estavam ainda dividindo o valor, quando perceberam a aproximação de algumas pessoas. Carlinhos, Rodrigo e Luiz se esquivaram, indo cada um para seu lado. Mateus e Pedro, os mais jovens, que deveriam ter idade inferior a dez anos, continuaram ali.

As pessoas se sentaram ao lado dos garotos e iniciaram uma conversa amistosa. Depois de certo grau de entrosamento, os adultos indagaram sobre a origem do dinheiro que os garotos possuíam. Mateus, com um ar de inibição, resolveu nada falar. Pedro, ao contrário, revelou que tinha conseguido o dinheiro através de doações e não parou por aí. Informou, ainda, que do valor de 12 mil cruzeiros, parte que lhe coube da divisão, ficaria com sete mil, pois os outros cinco ele entregaria a uma pessoa de nome... Pedro olhou para Mateus e resolveu deixar a frase incompleta. Os adultos insistiram em saber o nome da pessoa para qual iria parte do dinheiro; em resposta, as crianças saíram correndo, cada qual para um lado (MÁFIA..., 1984, p. 1).

Esta cena virou notícia no jornal Tribuna Criciumense, com o título: "A máfia da esmola invade Criciúma”. Essa não foi a primeira peça que tratava a temática na década de 1980, mas era uma peça de destaque, uma reportagem de capa que ocupava praticamente a página inteira, dividindo espaço apenas com duas notas de publicidade, aliás, bem pequenas. A ênfase dada para essa notícia marcava o reaparecimento de uma situação que era considerada equacionada na cidade, $\mathrm{o}$ ato de mendigar.

\footnotetext{
* Doutoranda do Programa de Pós-Graduação em História na Universidade do Estado de Santa Catarina (UDESC).

E-mail: lismachieski@gmail.com
} 
No período a temática da mendicância ganhou destaque no jornal Tribuna Criciumense, o qual trouxe o assunto em algumas de suas páginas, assim como soluções foram apontadas para a erradicação de tal demanda. Nesse sentido, o objetivo desse trabalho esteve focado em analisar a construção discursiva da imprensa em relação às chamadas crianças pedintes, ou seja, sobre infantes que circulavam pelas ruas da cidade de Criciúma e pediam dinheiro para os transeuntes, na década de 1980.

O jornal Tribuna Criciumense, fonte documental que subsidia esta narrativa, não foi selecionado de maneira aleatória, algumas informações são relevantes para a compreensão da escolha. Primeiro, deve-se destacar que esse jornal foi, e ainda é, um dos principais jornais cuja edição ocorria no município de Criciúma e região. Outro fator de relevância foi a facilidade de acesso a uma longa série. O jornal Tribuna Criciumense, embora com algumas edições ausentes, encontravase praticamente completo no acervo do Arquivo Histórico Pedro Milanez.

O jornal Tribuna Criciumense abordava, desde a década de 1960, a temática da mendicância. A primeira peça que justifica a afirmação foi publicada no final da década de 1960, mais precisamente em 1965:

Não há dia, não há hora em que não batam em nossa porta ou vejamos às ruas velhos maltrapilhos e menores esfaimados que com seus olhos tristes nos pedem um troco, um pão. Dandonos de volta pela caridade momentânea o esperançoso "Que Deus lhe ajude"! A mendicância sempre existiu em nossa cidade, mas de uns tempos pra cá tem aumentado em proporções alarmantes e urge que enfrentemos este fato, como um novo e grave problema que deve ser selecionado. (MENDICÂNCIA..., 1965, p. 1).

Alguns anos depois, em março de 1972, a reportagem apresentava indícios de que meninos e meninas circulavam pelas ruas da cidade em busca de alguns trocados. A notícia, intitulada "Criciúma poderá contar com asilo de menores", apresentava a reivindicação de uma instituição que "pudesse abrigar os menores delinquentes e os menores esmoleiros perambulantes" (CRICIÚMA..., 1972, p. 12). Se existia a reivindicação, é provável que as crianças e os adolescentes circulassem pelas ruas da cidade, mesmo sem aparecer nas páginas dos jornais de maneira direta, abordados em situações cotidianas, como circular pelas ruas e pedir esmolas.

Pouco mais de um ano, em dezembro de 1973, uma reportagem, intitulada "Menores continuam preocupando", apresentava o desaparecimento do considerado problema da mendicância, como aponta o fragmento:

O problema da mendicância em nossa cidade, felizmente já não existe; a Associação Feminina de Assistência Social, com desprendimento e boa vontade, conseguiu contornar a situação, banindo do nosso meio os esmoleres [sic] de outros municípios, enquanto que os realmente necessitados de nosso município estão sendo ajudados por aquela instituição. (MENORES..., 1973, p. 3).

Embora o texto não demonstrasse quais foram as medidas adotadas pela Associação Feminina de Assistência Social, ele apontava o problema da mendicância como solucionado, os pedintes não mais circulavam pelas ruas. É possível que essa erradicação estivesse associada ao fato que resultou na ausência dos infantes pedintes das páginas dos jornais (e quiçá das ruas) durante toda a década de 1970. Afinal, foram apenas duas reportagens que tratavam de tal temática, a primeira datava o ano de 1972; a segunda, o ano de 1973. Depois disso, no decorrer de toda a década de 1970, nada mais sobre a temática havia sido publicado, nenhuma reportagem, nenhuma notícia, nenhuma frase que evidenciasse a circulação de crianças pedintes pelas páginas do jornal. No entanto, na década de 1980, as crianças pedintes voltaram a circular pelas ruas da cidade, segundo as notícias do jornal Tribuna Criciumense. Crianças como Carlinhos, Rodrigo, Mateus, Pedro e Luiz, meninos e meninas, em uma larga faixa etária, circulavam pelas ruas da cidade de Criciúma em busca de sobrevivência. 


\section{As crianças, as esmolas, o jornal}

Aos poucos, os protagonistas desta narrativa histórica iniciavam sua circulação por entre as páginas do jornal Tribuna Criciumense. Eram crianças e adolescentes pobres que circulavam, moravam, corriam, brincavam e principalmente esmolavam nas ruas da cidade de Criciúma e região, durante a década de 1980 .

O jornal, ao ser utilizado como fonte, deve ser entendido como algo produzido por um sujeito que está inserido em determinado contexto, temporal e territorial, e impregnado pelos discursos que nele circulam. Da mesma maneira, considera-se o discurso jornalístico como formador de opiniões, resultando na influência que exerce sobre seus leitores. Percebe-se, assim, uma via de mão dupla, ou seja, o discurso jornalístico pode ser considerado, ao mesmo tempo, como fruto de um contexto que se alimenta dos vários outros discursos que nele circulam, assim como é responsável pela formação de opinião das pessoas que vivem no contexto em questão. É por meio desta partilha, de quem escreve e de quem lê, que se produzem outros discursos e se constroem sujeitos. Ao utilizar os jornais, deve-se levar em conta que sua produção é realizada por critérios objetivos e subjetivos. Compartilha-se, assim, a ideia de Silvia Helena Zanirato, segundo a qual:

Todo o jornal tem uma perspectiva que orienta o modo de produzir a notícia, de veicular a informação, de propagar ideias e valores culturais, de forma que os fatos registrados não se constituem em verdades, mas sim em construções humanas, onde há toda uma subjetividade implícita. Por detrás de toda a notícia registrada subjaz uma "visão de mundo", dos jornalistas e dos proprietários do jornal, o que implica em reconhecer que as reportagens precisam ser avaliadas enquanto linguagens produtoras de significados em relação a uma situação contextualizada historicamente. (1999, p. 327).

Nesse espaço, cabe apresentar o jornal Tribuna Criciumense e sua visão de mundo. Tribuna
Criciumense era um jornal ligado à elite da cidade, geralmente de propriedade de grandes grupos carboníferos. Fundado em 1955, por José Pimentel, o jornal teve uma tiragem semanal até 1999 , quando passou a ser publicado diariamente. Sua longa trajetória fez com que fosse adquirido por diferentes grupos, tais como, o Grupo Catão e a Companhia Brasileira Carbonífera Araranguá (MACHADO; TORRES, 2000 , p. 80 ). Inicialmente, sua circulação se restringia ao município de Criciúma, e somente no final da década de 1970 se inseriu em outras cidades da região.

O jornal tinha, em média, dez páginas, podendo chegar a 16. Não era organizado por seções, mas sempre manteve o editorial na página dois. O Tribuna Criciumense tinha como foco notícias da cidade, e raramente tratava de fatos em esfera estadual e/ou federal. As matérias, em sua maioria, não levavam assinaturas e havia algumas colunas, mas estas não eram fixas.

No que se refere às reportagens, foram identificadas 61 peças que abordavam a temática da infância nas páginas do jornal Tribuna Criciumense, em sua maioria curtas e sem fotografias. Dentre esse número, apenas seis peças abordavam a temática da mendicância de crianças e adolescentes pelas ruas da cidade de Criciúma, durante a década de 1980. As publicações aconteceram de maneira anual, nos cinco primeiros anos da década, sendo que no quinto ano foram publicadas duas peças. O menor pedinte, da década de 1970, estava novamente em cena; porém, com uma nova denominação: criança pedinte.

A peça utilizada para abrir este artigo não foi a primeira a tratar da temática na década de 1980 , mas foi a primeira capa que teve seu espaço utilizado na íntegra para tratar de assuntos relacionados ao público infantojuvenil. No entanto, é importante frisar que a preocupação do jornal não parecia estar relacionada ao bem-estar das crianças, mas ao problema que elas criavam ou criariam, num futuro próximo, para a imagem da cidade. Cabe destacar que, em grande parte da reportagem de 18 de março de 1972, usou-se a expressão "garotos" quando se referiria aos cinco personagens do banco da praça; mas, em dois momentos específicos, a peça fez uso 
da expressão "menor", especialmente ao citar um possível aliciamento sobre essas crianças. Eis o trecho:

Hoje essas inocentes crianças são
ludibriadas para tomarem parte do
plano infame, amanhã ou depois
poderão ser facilmente aliciadas e
treinadas para executar pequenos
assaltos em residências, casas
comerciais e até mesmo trabalhando
no centro da cidade e nos pontos
de maior movimentação como
trombadinhas. Está na hora de alguém
fazer alguma coisa para acabar com
essa máfia de aliciadores de menores,
caso contrário, consequências
piores poderão advir futuramente.
(CRICIÚMA..., 1972, p. 12).

A associação entre esmolar e furtar é uma característica das reportagens selecionadas, tendo como principal personagem os menores pedintes. $\mathrm{O}$ ato de furtar viria como uma consequência do esmolar. Aqui cabe mencionar o chamado "ciclo da marginalização", termo utilizado desde a década de 1970, e que ganhou maior ênfase com a Comissão Parlamentar de Inquérito do Menor Abandonado, ou como ficou conhecida CPI do Menor, em 1975, que tinha por objetivo principal a investigação sobre o problema da criança e do menor carente. A utilização desse termo teve continuidade, sendo empregado recorrentemente durante toda a década de 1980. Exemplo disso foi a Campanha da Fraternidade de 1987, que pautada na CPI do Menor, problematizava tal assunto. E assim, o discurso sobre o ciclo da marginalização tornou-se pauta de discussão em diferentes grupos e segmentos do país, chegando, também, até as mídias impressas de âmbito nacional.

O ciclo de marginalização do menor era resultado de algumas mudanças na realidade social do país. Entre 1940 e 1970 uma parcela significativa da população vivia na condição de pobreza, fator aguçado pela vinda em massa de pessoas do meio rural para o espaço urbano. De acordo com Frontana:

O crescimento desmensurado e não-planificado $[$ sic $]$ das cidades, conjugado aos mecanismos de espoliação de impostos pelo modelo de desenvolvimento capitalista adotado [...], produziu efeitos catastróficos do ponto de vista social. Parcelas consideráveis da população migrante e nativa de trabalhadores foram se aglomerando cada vez mais nas periferias dos grandes centros urbanos, formando os chamados "cinturões de miséria" ou "anéis de pobreza" [...]. Essas populações passaram a conviver com privações de toda a ordem, engrossando os índices de miséria urbana. (FRONTANA, 1999, p. 66).

A marginalização dessas famílias migrantes e pobres culminaria na marginalização das crianças como vítimas de inúmeras carências e perigos. Por sua vez, o ciclo da marginalização do menor, por tratar de um processo social, iniciava com o menor em via de marginalização social e culminava no menor infrator, considerando a criminalidade o grau máximo desse ciclo.

Era fácil perceber, embora não aparecesse de maneira direta, a presença do ciclo da marginalização no discurso jornalístico, o ciclo composto pelo menor abandonado, menor pedinte, menor delinquente se fazia presente no jornal Tribuna Criciumense, a considerada infância perigosa ou em vias de o ser. No entanto, mais uma vez, faz-se necessário afirmar que a preocupação não se pautava na criança ou no adolescente, em seus direitos; mas, no quanto a circulação dessas crianças pelas ruas incomodava a cidade.

Nesse período a cidade de Criciúma ainda respirava os ares de modernidade da década anterior, tempos de prosperidade. Segundo o historiador Dorval do Nascimento (2004, p. 390), nesse momento houve um grande crescimento da atividade carbonífera, que pode ser associado à crise do petróleo ocorrida entre 1973 e 1979. Junto com o ar poluído pelos resíduos do carvão, era possível aspirar o ar de modernidade que se instalava na cidade: a retirada da estrada ferroviária, a inauguração da Avenida Axial, a rodoviária da cidade e, por fim, no último ano da década, 1979, a Praça Nereu Ramos era transformada em calçadão e ganhava status de "sala de estar da comunidade". 
Possivelmente por isso, muito incomodava a circulação dessas crianças pelas ruas da cidade; afinal, era ali nas imediações da praça onde elas se concentravam, ali sobre os desenhos petit pavet que essas crianças, consideradas mal vestidas, buscavam algumas moedas. Foi sobre os bancos dessa praça que os cinco meninos, personagens desse artigo, contavam o dinheiro depois de um dia cheio de corre-corre.

A peça publicada em fevereiro de 1981, além de orientar para a não colaboração com os infantes pedintes, apresentava a situação de mendicância infantil como um quadro constrangedor para a realidade da cidade, como aponta o recorte:

Crianças na faixa etária de cinco a doze anos, estão novamente batendo de porta em porta mendigando a caridade pública. O surgimento de novos esmoleiros e de crianças esfarrapadas pelas ruas centrais da cidade recompõe um quadro constrangedor, que há três anos começou a ter mudada sua imagem. (CRIANÇAS..., 1981, p. 9).

Outros fatores devem ser observados nesse fragmento de 1981. O primeiro fator é a faixa etária das crianças pedintes, compreendida entre cinco e 12 anos. E aqui poderíamos novamente pensar no chamado ciclo da marginalização, ou seja, o que o jornal buscava evidenciar com essa informação? $\mathrm{O}$ que acontecia com as crianças pedintes após completarem 12 anos? Os jornais divulgavam o discurso de que dar esmolas era um meio de converter as crianças em futuros marginais, com probabilidade de "vida fácil", sem estimular o trabalho; assim, elas seriam lançadas para os pequenos furtos, um ciclo constante. É exatamente nesse ponto que se apresentavam as orientações para não doação de esmolas e, além disso, o encaminhamento a instituições que pudessem resolver o considerado problema, um exemplo disso aparece no fragmento a seguir:

A população poderá contribuir para a solução desse problema, encaminhando essas crianças às entidades assistenciais que se ocupam do atendimento ao menor em nossa cidade, ou comunicando os fatos às autoridades competentes. Dar esmolas é converter essas crianças em futuros marginais. (CRIANÇAS..., 1981, p. 9).

Em dezembro de 1983, na edição n. 1463 do Jornal Tribuna Criciumense, foi publicada uma notícia que em quase nada se diferia das anteriores, principalmente no que dizia respeito às orientações de como proceder junto aos pedintes, ou seja, não doar. No entanto, essa reportagem trazia uma nova informação, o fato de que as crianças aceitavam somente dinheiro:

Cresce assustadoramente o número de pedintes no centro criciumense, principalmente nas imediações da Praça Nereu Ramos, no calçadão. São crianças portando cartazes feitos de papelão, papel comum e outras formas de solicitações à população, na tentativa de arranjar algum trocado. Dirigidas por adultos essas crianças ficam perambulando pelas ruas centrais e calçadão até a calada da noite, puxando o braço do transeunte, solicitando apenas dinheiro e, negando-se a pegar comida, que em muitos casos é oferecida. Se não bastassem as crianças, sujas de propósito para chocar os indefesos. (PEDINTES..., 1983, p. 9).

Essa reportagem deu grande ênfase a essa informação ao afirmar que de nada adiantava tentar dar qualquer outra coisa, mesmo que alimentação, uma vez que as crianças e os adolescentes recusavam, pois queriam somente dinheiro. Merece, também, destaque a inversão de papeis feita pelo articulista, as vítimas não eram as crianças, mas os possíveis doadores, na reportagem o ato de estar sujo e maltrapilho aparece como situação premeditada, uma tática das crianças e dos adolescentes para chocarem as pessoas que por ali passavam, e assim conseguirem o objetivo que era a caridade alheia. Aliás, a expressão "abuso da caridade alheia" apareceu em todas as peças que tratavam da mendicância praticada pelo público infantojuvenil. Outra informação importante dessa reportagem foi o número de crianças pedintes:

Apesar do esforço desmedido e apreciável que a AFASC - Associação 
Feminina de Assistência Social de Criciúma vem desenvolvendo para combater a invasão de pedintes esmoleiros cadastrando-os e prestando toda a assistência indispensável para não circularem pelo centro da cidade, temos notado o aparecimento acentuado de quase uma centena de garotos passando a usufruir da bondade alheia. (PEDINTES..., 1983, p. 9).

O jornal apontava que aproximadamente uma centena de crianças circulava pelas ruas da cidade pedindo esmolas, um número expressivo para a cidade de Criciúma. Será que esse número era real? Existem dois trajetos que podem ser percorridos. O primeiro trajeto considera que esse fato realmente procedesse, pois o contexto da época permite essa interpretação. $O$ segundo pode estar associado ao fato de dar expressividade à reportagem, uma tentativa de fazer com que a população se atentasse ao que acontecia nas ruas da cidade. Desenvolverei as duas possibilidades.

Neste período, o carvão catarinense passava por uma grave crise. Publicada na edição n. 1.614, em 17 de agosto de 1985, a matéria de capa do jornal Tribuna Criciumense alertava sobre possíveis demissões devido à crise do carvão, conforme o fragmento: A crise do carvão catarinense e de outros estados brasileiros, poderá ter consequências graves, principalmente na Região Carbonífera, onde os mineradores poderão demitir mais de dois mil mineiros, o que vai gerar sério conflito social no sul de Santa Catarina (CRISE..., 1985, p. 1).

O desenvolvimento econômico da cidade estava fortemente ligado a um processo de crescimento populacional, uma vez que muitas pessoas se dirigiam para Criciúma em busca de trabalho nas mineradoras. De acordo com o historiador Emerson César de Campos, em 1987:

Após uma redução considerável dos subsídios que por mais de 40 anos foram fornecidos pelo governo federal à indústria extrativa do carvão mineral, o setor carbonífero se retraiu abruptamente, provocando desemprego e gerando uma crise social de grandes proporções. Após um período de intensas reivindicações e lutas, promovidas por movimentos sociais, sindicatos, organizações de bairros, imprensa e pelo próprio empresariado local, a cidade deixou de ser divulgada como a capital brasileira do carvão (2007, p. 1).

Essa baixa na extração do carvão, na cidade de Criciúma, repercutiu de maneira direta na redução do número de empregos no final da década de 1980. É provável, também, que tenha contribuído para o crescente número de crianças a vagar pelas ruas da cidade, naquela época.

E se isso em nada alterasse a realidade da cidade em relação às crianças pedintes, ou então, se não atingisse as dimensões apresentadas pelo jornal? Qual a intenção do Tribuna Criciumense em evidenciar o número, cada vez maior, de crianças pedintes? Quero destacar que a intenção não é entender as notícias como reveladoras de um real, mas pensar que produzem "verdades", e estas, por sua vez, são construídas mediante a conjuntura de um determinado espaço e temporalidade. A construção e a ênfase em uma notícia têm intencionalidades que, por sua vez, estão associadas à visão do jornal. Se em 1983 era aproximadamente 100 o número de crianças pedintes que circulava pelas ruas, o que as fez não mais circularem pelos jornais depois de 1985 ?

No ano de 1985, foi publicada a última reportagem que abordou a temática da mendicância realizada por crianças e adolescentes. Essa reportagem trazia um diferencial, o uso de voz especializada, Dilzeda Coral Benedet, representante da Fundação Nacional do Bem-Estar do Menor (FUNABEM) em Santa Catarina, que afirmava: "Entregar ou dar esmolas a um menor abandonado só iria contribuir para aumentar o grave problema existente no país" (DIZELDA..., 1985, p. 6). O discurso é, conforme Foucault (2009), assumido como um conjunto de práticas que instituem objetos, estratégias e ações sobre os quais de alguma forma se manifestam. Tais práticas, por fim, legitimam enunciados - textos e/ou falas - e enunciadores quem os produz, a voz autorizada. A utilização da fala da representante estadual da FUNABEM é dar a notícia legitimidade, é uma orientação pautada 
em uma fonte, em uma instituição destinada ao atendimento ao público infantojuvenil.

Em relação à solução, não foi possível identificar nos jornais se as crianças pedintes pararam de circular pelas ruas em busca de alguns trocados. Sabe-se, porém, que entre as páginas do Tribuna Criciumense elas não mais circularam. Uma das hipóteses para uma possível solução esteja associada à criação do Abrigo de Menores da cidade (AME).

\section{O jornal e a busca por uma solução}

Todas as peças que tratavam sobre a temática de crianças e adolescentes pedintes publicadas, durante a década de 1980, no jornal Tribuna Criciumense seguiam o mesmo discurso de orientação para a população: não dar esmolas. Além disso, quatro dessas reportagens fizeram menção ao trabalho realizado pela AFASC. No entanto, nenhuma dessas possíveis soluções parecia resolver o problema apontado pelo jornal, embora algumas campanhas de erradicação da mendicância tivessem sido organizadas.

A última reportagem que abordou a questão da circulação de crianças e adolescentes pedintes foi datada de 1985, um ano depois da reportagem que trazia a informação sobre o Abrigo de Menores. A peça, publicada em agosto de 1984, em síntese, apresentava a ideia do projeto que era a de abrigar menores. Um grupo de pessoas da comunidade criciumense uniu-se e em uma das reuniões foi dada a sugestão de utilizar o espaço ocupado pelo Centro de Recuperação Física, construído em 1972 e funcionado por apenas três meses.

Era necessária, porém, a autorização dos 800 sócios, tendo em vista que, mesmo desativada, aquela instituição legalmente ainda existia. Em 27 de agosto de 1983 foi realizada uma assembleia com os sócios. Nesta reunião foi feita a doação de alguns dos títulos, o que conferia direito de uso, por tempo indeterminado, e de reforma do Centro de Recuperação Física para abrigar menores. A reforma que começou ainda em agosto e durou até final de abril do ano seguinte, 1984. O abrigo passou a funcionar a partir do dia 5 de maio, com atendimento exclusivo para meninos. A manutenção dependia exclusivamente de doações da comunidade. Segundo Maria Lúcia Gonçalves, diretora do abrigo, neste período eram "[...] atendidas 16 crianças, na faixa etária de 5 a 12 anos, com alimentação, roupas, dentistas e cuidados médicos" (ABRIGO..., 1984, p. 5).

Ainda nessa peça a diretora informava sobre o objetivo da instituição, que era " [...] abrigar as crianças soltas pelas ruas de Criciúma, mesmo aquelas que tenham passagem pela polícia e que se encontram em liberdade. Pretendemos também abrigar os órfãos, aquele que a família não dá mais conta" (ABRIGO..., 1984, p. 5). Neste fragmento, podemos observar que a intenção era retirar as crianças que circulavam pelas ruas da cidade, institucionalizando-as.

Em pouco mais de três anos, em 1988, outra peça era publicada. $O$ texto passava a informação de que naquele momento eram 28 os menores abrigados. Em três anos o número de crianças praticamente havia dobrado com relação às atendidas inicialmente, e por conta disso - desse aumento no número de crianças - a instituição passava por dificuldades. Entre doações de materiais para revestimento do chão, móveis, dentre outras utilidades que poderiam contribuir com seu bemestar, a peça terminava com o apelo de Albertina Thomas, diretora, às mulheres que dispusessem de tempo: pedia que viessem "dar um pouco de si aos pequeninos" (ABRIGO..., 1988, p. 9).

Durante a década de 1980 as "crianças pedintes" foram apresentadas como crianças, mas que precisavam de disciplina para que não se transformassem, no futuro, como apontavam as peças, em "marginais". Era preciso tirá-las das ruas. Uma possível solução foi o Abrigo de Menores. Esta parece ter sido uma possibilidade considerada. Mas, além disso, é preciso evidenciar as mudanças que começavam a se operar na sociedade brasileira, seja no plano do discurso, seja no do social. Afinal, nesse período surgiram vários movimentos sociais, oriundos de diversas matizes ideológicas, que colocavam em pauta a discussão dos direitos políticos, civis e sociais. 
Como exemplo desta mobilização, podese citar o Movimento Nacional de Meninos e Meninas de Rua (MNMMR) que, fundado em 1985, agregava educadores(as), militantes de diversas áreas que, somados aos meninos e às meninas em situação de rua, buscavam pelos direitos da criança e do adolescente. A MNMMR defendia a ideia da criança e do adolescente como sujeitos de direitos, diferentemente de outros discursos, circulantes nos primeiros anos da década de 1980, que concebiam crianças e adolescentes como objeto de proteção social, de controle, disciplinamento e repressão social (PINHEIRO, 2005, p. 169).

A preocupação com a situação em que se encontravam as crianças e os adolescentes do Brasil, neste período, mobilizou a criação da Pastoral do Menor. Segundo a socióloga Ângela Pinheiro, as atividades iniciaram-se na arquidiocese de São Paulo, em 1978, espalhando-se por inúmeras dioceses do país, principalmente nos primeiros anos da década de 1980. Além da criação da pastoral, a Igreja Católica elegeu a criança como temática para a Campanha da Fraternidade de 1987.

O discurso e as discussões propostas pelos movimentos sociais apenas iriam chegar ao jornal Tribuna Criciumense na década seguinte. Somente a partir dos anos 1990 que se começou, de maneira paulatina, a pensar o considerado menor como criança e adolescente e na garantia de seus direitos.

\section{Considerações finais}

Como o jornal Tribuna Criciumense noticiava questões relativas às crianças e aos adolescentes pedintes? Desde a década de 1960, as crianças e os adolescentes pedintes foram apresentados como um problema para a sociedade. Ambos estavam fadadas ao ciclo de marginalização (abandonado, pedinte, infrator), discurso constante no período. Em pouco tempo, e se não houvesse intervenções, tornar-se-iam menores delinquentes. Essa associação entre a mendicância e a criminalidade era a base do ciclo da marginalização. Na década de 1980, apesar dos movimentos civis nacionais e internacionais, o discurso do jornal Tribuna Criciumense continuava propalando moralidade. E esse discurso utilizado por este jornal continuava impregnado de valores morais e tinha por objetivo retirar as crianças e os adolescentes das ruas, mas, principalmente, livrar as ruas e as pessoas que nelas transitam do mal social representado por estas crianças.

\section{Nota}

1 Embora os jornais, sejam fontes de domínio público, os nomes aqui utilizados são fictícios.

\section{Referências}

ABRIGO de menores de Criciúma atende 16 crianças. Jornal Tribuna Criciumense. Criciúma n. $1.500,7$ jul. 1984 , p. 5 .

ABRIGO de menores pede socorro. Jornal Tribuna Criciumense. Criciúma n. 1.871, 18 jun. 1988, p. 9.

CAMPOS, E. C. de. Estrangeiros em Casa: (re)sentimentos, impressões e identificações produzidas pelos emigrantes brasileiros clandestinos nos Estados Unidos, quando de volta para Santa Catarina (1995-2005). In: ANPUH XXIV SIMPÓSIO NACIONAL DE HISTÓRIA, 2007, São Leopoldo, RS. Anais do XXIV Simpósio Nacional de História - História e multidisciplinaridade: territórios e deslocamentos. São Leopoldo: Unisinos, 2007. p. 1-8. Disponível em: <https://anais.anpuh.org/?p=17524>. Acesso em: 15 mai. 2017.

CRIANÇAS voltam a pedir esmolas. Jornal Tribuna Criciumense. Criciúma, n. 1300, 7 fev. 1981, p. 9.

CRICIÚMA poderá contar com asilo para menores. Jornal Tribuna Criciumense. Criciúma, n. 870, 18 mar. 1972, p. 12.

CRISE pode acarretar em mais demissões. Jornal Tribuna Criciumense. Criciúma, n. 1.614, 17 ago. 1985, p. 1.

DIZELDA diz que menor não deve receber esmolas. Jornal Tribuna Criciumense. Criciúma, n. 1602, 07 ago. 1985, p. 6. 
FOUCALT, M. A ordem do discurso. 18. ed. São Paulo: Edições Loyola, 2009.

FRONTANA, I. C. R. Crianças e adolescentes nas ruas de São Paulo. São Paulo: Edições Loyola, 1999.

MACHADO, A.; TORRES, O. História da comunicação no Sul de Santa Catarina. Criciúma, SC: BTC, 2000.

MÁFIA da esmola invade Criciúma. Jornal Tribuna Criciumense. Criciúma, n. 1.484, 2 maio 1984, p. 1.

MENDICÂNCIA atinge proporções alarmantes. Jornal Tribuna Criciumense. Criciúma, n. 497, 30 jan. 1965, p. 1.

MENORES continuam preocupando. Jornal Tribuna Criciumense. Criciúma, n. 964, 29 dez. 1973, p. 3.
NASCIMENTO, D. A produção histórica e cultural da região carbonífera de Santa Catarina, 1880-1930. In: FILHO, A. G. Memória e Cultura do Carvão em Santa Catarina. Florianópolis: Cidade Futura, 2004. p. 383-394

PEDINTES invadem Criciúma. Jornal Tribuna Criciumense. Criciúma, n. 1463, 10 dez. 1983, p. 9.

PINHEIRO, Â. Criança e adolescente no Brasil: porque o abismo entre a lei e a realidade. Fortaleza: Editora Universidade Federal do Ceará, 2005.

ZANIRATO, S. H. A documentação fotojornalística na pesquisa histórica. Trajetos: Revista de História UFC, Fortaleza, v. 2, n. 4, p. 205-2018, 2005. Disponível em: <http://dc178.4shared.com/ doc/XfWdVAMM/preview.html>. Acesso em: 15 maio 2017 . 